\title{
THE CONDITION OF ORAL HEALTH AND CHOSEN SALIVA PARAMETERS OF PEDIATRIC PATIENTS AFTER HEART TRANSPLANT: PRELIMINARY REPORT
}

\author{
Iwona Wysoczańska-Jankowicz', Karolina Jones', Beata Wierucka-Młynarczyk², Beata Chodór ${ }^{3}$, Lidia Postek-Stefańska' \\ 'Department of Pediatric Dentistry, Faculty of Medical Sciences in Zabrze, Medical University of Silesia in Katowice, Poland \\ ${ }^{2}$ Department of Periodontal Diseases and Oral Mucosa Diseases, Faculty of Medical Sciences in Zabrze, Medical University of Silesia in Katowice, Poland \\ ${ }^{3}$ Department of Congenital Heart Defects and Paediatric Cardiology, SMDZ in Zabrze, Medical University of Silesia in Katowice, Silesian Centre for Heart \\ Diseases, Zabrze, Poland
}

\begin{abstract}
INTRODUCTION: The number of heart transplant in pediatric patients is constantly growing. Due to immunosuppressive therapy, there is an increased potential for oral lesions that may require special dental treatment. Decreased responses of the immune system can lead to a higher chance of odontogenic infection.

ОвJеCTIVEs: The aim of the study was to evaluate dentition, condition of gingiva, mucous membrane, condition of saliva, and level of oral hygiene in children after heart transplant.

MATERIAL AND METHODs: Heart transplant patients were examined extraorally and intraorally for pathological lesions. Decayed, missing, filled teeth (DMFT) and decayed, missing, filled surfaces (DMFS) indexes were used to assess the deciduous and permanent teeth. The periodontium was evaluated using gingival index (GI), modified sulcus bleeding index (mSBI), and gingival overgrowth index (GOI). Oral hygiene was evaluated with plaque index (Pl-I) and approximal plaque index (API). The saliva-check buffer by GC was used to measure the secretion speed $(\mathrm{ml} / \mathrm{min})$ to evaluate the $\mathrm{pH}$ and buffering abilities of the saliva.

RESULTS: The condition of primary and secondary dentition was better in the research group than in the control group. In the extraoral and intraoral examination, no major pathological changes were found. In both groups, mean hygiene level (Pl-I) was at average level. However, level of hygiene in the interproximal spaces (API) was worse in the research group. No gingiva overgrowth or bleeding were noticed. Two children had mild gingivitis. All patients had normal stimulated saliva secretion (> $5.0 \mathrm{ml} / \mathrm{min}$ ). Averaged saliva $\mathrm{pH}$ was 6.62 .

ConcLusions: Oral health is very important for heart recipients. All patients after heart transplantation should be provided with proper dental care. Due to permanent immunosuppression, all inflammatory changes in the oral cavity should be treated as soon possible.
\end{abstract}

KEY wORDS: heart transplantation, oral hygiene, oral health, child, immunosuppression.

J Stoma 2020; 73, 1: 22-26

DOI: https://doi.org/10.5114/jos.2020.94171

\section{INTRODUCTION}

Heart transplant is often a necessary treatment for severe decompensated heart failure. Children after heart transplantation are constantly undergoing immunosuppressive therapy, which may cause many different complications. The decrease of specific cell immunity in patients after an organ transplantation is a significant

JOURNAL OF STOMATOLOGY CZASOPISMO STOMATOLOGICZNE

AdDRESS FOR CORRESPONDENCE: Karolina Jones, Department of Pediatric Dentistry, Faculty of Medical Sciences in Zabrze, Medical University of Silesia in Katowice, Poland, e-mail: karolina7jones@gmail.com

ReCEIVED: 20.12.2019 • ACCEPTED: 13.03.2020 • Published: 25.03.2020 
cause of the impairment of local defense mechanisms, which increases the susceptibility of the periodontium and oral mucous membrane to infection [1-4]. Most common infectious lesions found in oral cavity are angular cheilitis, herpetic stomatitis, hairy leucoplakia, geographic tongue, fungoid disease, aphthae, gingivitis, and periodontitis. Non-infectious immunosuppressive therapy complications are drug-induced gingival overgrowth (observed mostly as cyclosporine A side effect) and lymphoproliferations $[5,6]$. Infections, which often are resistant to pharmacological treatment, may lead to different complications such as internal organ damage (e.g. gastrointestinal complications) [7].

There have been few studies $[8,9]$ on the oral health of pediatric patients after heart transplantation. Transplantology is a rapidly developing branch of medicine, and the number of children who have undergone a heart transplantation is constantly growing. Therefore there is such a need to perform more studies concerning the condition of oral health in children who undergone heart transplantation. Immunosuppressive therapy, which is required to avoid rejection of transplanted organ by recipient's body, can cause numerous complications, with

TABLE 1. Characteristics of the examined population

\begin{tabular}{|c|c|c|}
\hline Number of patients & $\begin{array}{l}\text { Research group, } \\
\qquad n=10\end{array}$ & $\begin{array}{c}\text { Control group, } \\
\qquad \begin{array}{c}n=10\end{array}\end{array}$ \\
\hline \multicolumn{3}{|l|}{ Age $^{*}$ (years) } \\
\hline Together & $13.1(7-17)$ & $9.5(5-17)$ \\
\hline Female & $12.5(7-17)$ & $8.9(5-17)$ \\
\hline Male & $14(8-17)$ & $11(6-15)$ \\
\hline \multicolumn{3}{|c|}{ Age ${ }^{*}$ during transplantation (years) } \\
\hline Together & $7.9(0-17)$ & - \\
\hline Female & $6.17(0-13)$ & - \\
\hline Male & $10.5(0-17)$ & - \\
\hline \multicolumn{3}{|l|}{ Sex } \\
\hline Female & 6 & 7 \\
\hline Male & 4 & 3 \\
\hline
\end{tabular}

TABLE 2. Cause of transplantation and immunosuppressive drugs taken by heart transplant patients

\begin{tabular}{|l|c|}
\hline Heart disease & $\begin{array}{c}\text { Number } \\
\text { of children }\end{array}$ \\
\hline Dilated cardiomyopathy & 7 \\
\hline Cardiac insufficiency & 2 \\
\hline Arrhythmogenic right ventricular cardiomyopathy (ARVC) & 1 \\
\hline Drug type & 10 \\
\hline Tacrolimus & 5 \\
\hline Mycophenolate mofetil & \\
\hline
\end{tabular}

many occurring in the mouth. It is necessary to provide those patients with appropriate dental care. Since many pathological changes primarily appear in the oral cavity, there are an important sign for cardiologists to perform additional tests and/or modify the therapy [4].

\section{OBJECTIVES}

The purpose of the study was to evaluate the condition of dentition, gingiva, mucous membrane, condition of saliva, and the level of oral hygiene for patients between the ages of 3 to 18 -years-old that have undergone a heart transplantation.

\section{MATERIAL AND METHODS}

The study included ten patients hospitalized in the Department of Congenital Heart Defects and the Pediatric Cardiology of the Medical University of Silesia, Poland. The control group was examined in the Developmental Age Clinic of Academic Centre of Dentistry in Zabrze, Poland. Characteristics of the examined population are shown in Table 1. In the presented study, ten children after heart transplantations (six girls and four boys) and ten healthy children from the control group (seven girls and three boys) were examined. The average patient's age was 13.1 years old (12.5 years old for females and 14 years old for males) and 9.5-years-old in the control group (8.9 years old for females and 11 years old for males). The average age of patients undergoing heart transplantation was 7.9 years old (6.2 years old for females and 10.5 years old for males). The reasons for transplantation were dilated cardiomyopathy in seven patients, cardiac insufficiency in two patients, and arrhythmogenic right ventricular cardiomyopathy (ARVC) in one patient. Immunosuppressive drugs taken by patients are tacrolimus (all children) and mycophenolate mofetil (five of ten children) (Table 2). Parents or legal guardians of the children consented to perform a subjective examination, dental examination, and saliva testing. Children using dental prosthesis, orthodontic braces, or retainers were excluded from the examination. We prepared an examination form consisting of a survey about the child's medical history and oral hygiene. The extraoral examination consisted of face symmetry estimation, lymph node examination, presence of edema, testing for pathological lesions on skin and/or lips, and examination of temporomandibular joints (TMJ). In the intraoral examination, a dental mirror and a periodontal probe were used to examine the deciduous and permanent teeth. A surface teeth diagram was filled out and the decay, missing, filled teeth (DMFT) index [10] and the decayed, missing, filled surfaces (DMFS) index [10] were estimated for primary (dmft and dmfs) and secondary teeth (DMFT and DMFS). The condition of the mucous membrane, gingiva, and tongue were examined, and any pathological 
changes were noted. Oral hygiene was evaluated using the plaque index (Pl-I) [11] and the approximal plaque index (API) [12]. The periodontium was evaluated with the gingival index (GI) [11], the modified sulcus bleeding index (mSBI) [13], and gingival overgrowth index (GOI) [14]. The saliva-check buffer test by GC was performed on the saliva collected within a 5-minute period into a single-use cup. The secretion speed ( $\mathrm{ml} / \mathrm{min}), \mathrm{pH}$, and buffering abilities were observed for an estimation of the effectiveness of acid neutralization.

\section{RESULTS}

In the presented study, none of the examined children had face asymmetry; no edema or any pathological lesions on the skin nor on the lips were found. In temporomandibular joints examination, one child from research group had popping in both joints. In the control group, one child had clicking in both temporomandibular joints, and one child had enlarged and painful submandibular lymph nodes on the right side.

Intraoral examination revealed enlarged tonsils in one child from research group and in one child in the control group. Filiform papillae overgrowth was observed in one child from research group and in five children in the control group. One child from research group had fissured tongue.

The average DMFT index for permanent teeth was lower in the research group than in the control group (4.5 vs. 5.0 ), and the average DMFS index for secondary dentition in the research group was also lower (6.1 vs. 6.5). The average dmft index for deciduous teeth in children after heart transplantation was lower as well (4.0 vs. 7.0), and the average dmfs index for primary dentition in the research group was 8.75 and 16.85 in the control group. Details of DMFT, DMFS, dmft, and $\mathrm{dmfs}$ indexes are presented in Table 3 . The average plaque index (Pl-I) was similar in both groups (0.68 in children after transplantation and 0.65 in healthy children). The average approximal plaque index was higher in the research group (60\% vs. $46 \%$ ). The mean hygiene level for all examined children was between $62 \%$ and $42 \%$, which was estimated to be an average hygiene level. Six of ten transplant patients had poor hygiene, only three had rather good, and none had optimum level of oral hygiene. Children in the control group had better results in the cleanliness of interproximal spaces, with six of ten patients having average hygiene, three rather good, and only one patient was noted with poor oral hygiene level (Table 4). The average gingival index in research group was 0.05 for females and 0.07 for males. Two children after a heart transplantation (one female and one male) had mild gingivitis. None of the children from the control group had gingivitis; the gingival index indicated zero for all healthy patients (Table 5). The average modified sulcus bleeding index and the average gingival overgrowth index showed 0 for both groups. The amount of stimulated saliva secreted after 5 minutes of chewing a paraffin cube was normal $(>5.0 \mathrm{ml})$ for all children in the research group and for six children in the control group (three

TABLE 3. Average values of the decay, missing, filled teeth and the decayed, missing, filled surfaces indexes for deciduous and permanent teeth

\begin{tabular}{|l|c|c|c|c|c|c|}
\hline & \multicolumn{3}{c}{ Research group } & \multicolumn{3}{c}{ Control group } \\
\hline & Female & Male & All & Female & Male & All \\
\hline DMFT (average) & 3.30 & 6.25 & 4.50 & 4.30 & 7.00 & 5.00 \\
\hline Decayed (D) teeth & 1.00 & 0.75 & 0.90 & 1.50 & 1.00 & 1.33 \\
\hline Missing (M) teeth & 0 & 0 & 0 & 0 & 0 & 0 \\
\hline Filled (F) teeth & 2.33 & 5.50 & 3.60 & 2.83 & 3.67 & 3.11 \\
\hline DMFS (average) & 4.17 & 9.00 & 6.10 & 5.50 & 9.50 & 6.5 \\
\hline Decayed (D) surfaces & 1.00 & 2.00 & 1.40 & 1.67 & 1.00 & 1.44 \\
\hline Missing (M) surfaces & 0 & 0 & 0 & 0 & 0 & 0 \\
\hline Filled (F) surfaces & 3.16 & 7.00 & 4.70 & 3.83 & 9.00 & 5.56 \\
\hline dmft (average) & 3.00 & 5.00 & 4.00 & 6.16 & 12.00 & 7.00 \\
\hline Decayed (d) teeth & 1.00 & 1.00 & 1.00 & 3.17 & 6.00 & 3.57 \\
\hline Missing (m) teeth & 1.00 & 1.00 & 1.00 & 0.17 & 1.00 & 0.29 \\
\hline Filled (f) teeth & 1.00 & 3.00 & 2.00 & 2.83 & 5.00 & 3.14 \\
\hline dmfs (average) & 7.00 & 11.00 & 8.75 & 13.30 & 38.00 & 16.85 \\
\hline Decayed (d) surfaces & 1.00 & 3.00 & 2.00 & 8.17 & 22.00 & 10.14 \\
\hline Missing (m) surfaces & 5.00 & 5.00 & 5.00 & 0.83 & 5.00 & 1.43 \\
\hline Filled (f) surfaces & 1.00 & 3.00 & 2.00 & 4.33 & 11.00 & 5.28 \\
\hline
\end{tabular}


TABLE 4. Oral hygiene based on approximal plaque index (API)

\begin{tabular}{|l|c|c|c|c|c|c|}
\hline & \multicolumn{3}{c}{ Factor } & Fesearch group & \multicolumn{3}{c|}{ Control group } \\
\cline { 2 - 8 } & $59 \%$ & $62 \%$ & $60 \%$ & $48 \%$ & $42 \%$ & $46 \%$ \\
\hline API & 3 & 3 & 6 & 1 & 0 & 1 \\
\hline $100-70 \%$ - poor hygiene & 1 & 0 & 1 & 5 & 1 & 6 \\
\hline $69-40 \%$ - average hygiene & 2 & 1 & 3 & 1 & 2 & 3 \\
\hline $39-25 \%$ - rather good hygiene & 0 & 0 & 0 & 0 & 0 & 0 \\
\hline$<25 \%$ - optimum hygiene & & & All & & Male & \\
\hline
\end{tabular}

TABLE 5. Gingival index (GI) results

\begin{tabular}{|c|c|c|c|c|c|c|}
\hline \multirow[t]{2}{*}{ Factor } & \multicolumn{3}{|c|}{ Research group } & \multicolumn{3}{|c|}{ Control group } \\
\hline & Female & Male & All & Female & Male & All \\
\hline $\mathrm{Gl}$ & 0.05 & 0.07 & 0.06 & 0 & 0 & 0 \\
\hline $0.1-1.0$ - mild gingivitis & 1 & 1 & 2 & 0 & 0 & 0 \\
\hline 1.1-2.0 - moderate gingivitis & 0 & 0 & 0 & 0 & 0 & 0 \\
\hline 2.1-3.0 - severe gingivitis & 0 & 0 & 0 & 0 & 0 & 0 \\
\hline
\end{tabular}

TABLE 6. Oral hygiene, condition of the gingiva, saliva pH, buffering abilities of saliva, and stimulated saliva flow

\begin{tabular}{|c|c|c|c|c|c|c|}
\hline \multirow[t]{2}{*}{ Factor } & \multicolumn{3}{|c|}{ Research group } & \multicolumn{3}{|c|}{ Control group } \\
\hline & Female & Male & All & Female & Male & All \\
\hline Plaque index (PI-I) & 0.63 & 0.76 & 0.68 & 0.72 & 0.47 & 0.65 \\
\hline Modified sulcus bleeding index (mSBI) & 0 & 0 & 0 & 0 & 0 & 0 \\
\hline gingival overgrowth index (GOI) & 0 & 0 & 0 & 0 & 0 & 0 \\
\hline Saliva's pH & 7.04 & 6.85 & 6.26 & 6.65 & 7.4 & 6.88 \\
\hline Buffering ability & 10.67 (normal) & 11.33 (normal) & 11 (normal) & 12 (normal) & 12 (normal) & 12 (normal) \\
\hline Stimulated saliva flow (ml/5 min) & 7 & 7.67 & 7.33 & 4.14 & 5.3 & 4.5 \\
\hline
\end{tabular}

children from the control group had low secretion and one child had very low secretion). The average saliva $\mathrm{pH}$ was 6.26 in the research group and 6.88 in control group. Buffering abilities were normal for all examined patients. Two children from the research group would not cooperate and saliva test was not performed. Oral hygiene, condition of the gingiva, saliva $\mathrm{pH}$, buffering abilities of saliva, and stimulated saliva flow are presented in Table 6.

\section{DISCUSSION}

Organ recipients taking immunosuppressive drugs permanently are more prone to infections. These infections may manifest in the oral cavity, and the patients are more likely to develop lesions. In our study, the intraoral examination did not show any pathological changes in mucosa or tongue in contrast to other studies $[8,15$, 16]. Although it is important to point out the fact that in both Olczak-Kowalczyk et al. and Ansari et al. studies, more pathological changes were found in patients taking cyclosporine A (CsA) rather than tacrolimus. Our study confirms that tacrolimus induces less sides effects reflected in the oral cavity. Gingival overgrowth is most often related with CsA and rarely with tacrolimus or mycophenolate mofetil, which was confirmed in the present study as well as in other studies $[1,9,17,18]$.

The clinical evaluation of twenty patients showed similar conditions in both the research and control group's secondary teeth. The condition of deciduous teeth was better in the research group than in the control group, which was a good sign. Similar [2] or higher [1] DMFT and dmft results were discovered in other studies. However, the result of epidemiological research of oral health in Polish children at the age of 6 showed higher dmft level (5.4) [19]. In a research on the condition of dentition in Polish children aged 15, DMFT result was even higher (6.07) [20]. However, the results of DMFT, DMFS, dmft, and dmfs indicate that dental 
care of heart transplant patients is still not sufficient. It is a similar condition of oral health in Polish children at the age of 6 (only $14.4 \%$ of examined kids were free from caries) [19] and lower than the condition of oral health in 12-years-old Polish children (20.4\%) [21]. Male patients in both groups also had higher DMFT indexes than female patients.

It is known that various microbial species are present in the oral cavity and some of them (especially bacteria from Streptococcus sp.) are associated with bacterial endocarditis. Therefore, the mouth may be a possible source of odontogenic infection [8].

The oral hygiene level found in both groups was unsatisfying. Similar results were gathered by other authors [1]. However, the conditions of gingiva and periodontium were good in almost all examined children. Our study indicates better outcomes than found in other reports $[1,15]$, although most patients in OlczakKowalczyk et al. studies had been taking cyclosporine. Newer immunosuppressive drugs such as tacrolimus do not cause gingival overgrowth. Gingival hyperplasia can create conducive conditions for gingivitis (gingival overgrowth index for patients from our research was equal to 0 ). Gingiva bleeding was not present in any of examined patients.

\section{CONCLUSIONS}

Preventing oral diseases is a very important issue for patients after heart transplantation taking immunosuppressive drugs. Due to the fact that this treatment is irreversible and permanent, organ recipients should undergo regular dental examinations. All infectious changes in the oral cavity should be eliminated. It is crucial that all cavities need to be treated before they lead to pulp diseases. Preventing pulp and periodontal inflammation is especially important for high-risk patients such as patients after heart transplantation. Dentists need to remember that immune systems of heart recipients are weakened, and the patients are at greater risk of various systemic diseases and infections located in oral cavity. Frequently, the dental treatment plan needs to be consulted with the transplant physician. Both children and their parents should be educated about the importance of oral health. They need to be taught about the importance of the role of dental prophylaxis and appropriate hygienic methods as well as proper diet. Since the number of pediatric patients after heart transplantation is constantly growing, further studies concerning the condition of oral health are necessary.

\section{CONFLICT OF INTEREST}

The authors declare no potential conflicts of interest with respect to the research, authorship, and/or publication of this article.

\section{References}

1. Olczak-Kowalczyk D, Bedra B, Śmirska E, et al. Oral cavity changes dependent on different protocol of immunosuppression in patients after transplantation of high vascularity organs - a pilot study. Czas Stomatol 2006; 11: 759-768.

2. Olczak-Kowalczyk D, Pawłowska J, Śmirska E, et al. Assessment of mineralized teeth 's tissue status in developmental age patients after kidney or liver transplantation. Part I - Frequency and intensity of caries. Nowa Stomatol 2008; 3: 79-85.

3. Snydman D. Epidemiology of infections after solid-organ transplantation. CID 2001; 33: 5-8.

4. Szubińska-Lelonkiewicz D, Golecka-Bąkowska M, Osiak M. The algorithm of dental treatment in patients before and after organ transplantation. Dent Med Probl 2017; 54: 183-187.

5. Kurzeja M, Grabowska E, Grabowska M, et al. The evaluation of periodontal tissues and treatment needs in patients after heart transplantation. Nowa Stomatol 2002; 2: 99-104.

6. Maj S. Drug-induced blood dyscrasias. Postępy Nauk Med 2000; 4: 17-28.

7. Helderman J, Goral S. Gastrointestinal complications of transplant immunosuppression. JASN 2002; 13: 277-287.

8. Ansari F, Ferring V, Schulz-Weidner N, et al. Concomitant oral finings in children after cardiac transplant. Pediatr Transplant 2006; 10: 215-219.

9. Nappalli D, Lingappa A. Oral manifestations in transplant patients. Dental Research J 2015; 12: 199-207.

10. Olczak-Kowalczyk D, Szczepańska J, Kaczmarek U, et al. Współczesna stomatologia wieku rozwojowego. Med Tour Press International 2017; 264-267.

11. Löe H. The Gingival Index, the Plaque Index and the Retention Index Systems. J Periodontol 1967: 38: 610-616.

12. Olczak-Kowalczyk D, Szczepańska J, Kaczmarek U, et al. Współczesna stomatologia wieku rozwojowego. Med Tour Press International 2017; 394-395.

13. Mühlemann H, Son S. Gingival sulcus bleeding - a leading symptom in initial gingivitis. Helv Odontol Acta 1971; 15: 107-113.

14. Olczak-Kowalczyk D, Szczepańska J, Kaczmarek U, et al. Współczesna stomatologia wieku rozwojowego. Med Tour Press International 2017; 672.

15. Olczak-Kowalczyk D, Pawłowska J, Cukrowska B, et al. Local presence of cytomegalovirus and Candida species vs oral lesions in liver and kidney transplant recipients. Ann Transplant 2008; 13: 28-33.

16. Olczak-Kowalczyk D, Pawłowska J, Śmirska E, et al. Status of the oral mucosa in patients in development age after liver and kidney transplants. Nowa Stomatol 2008; 2: 58-64.

17. Olczak-Kowalczyk D. Gingival diseases in development age patients after solid organ transplantation (liver or kidney). Nowa Stomatol 2010; 1: 21-24.

18. Wondimu B, Nemeth A, Modeer T. Oral health in liver transplant children administred cyclosporin A or tacrolismus. Int J Paediatr Dent 2001; 11: 424-429.

19. Strużycka I, Wierzbicka M, Jodkowska E, et al. Stan zdrowia jamy ustnej oraz potrzeby profilaktyczno-lecznicze dzieci w wieku 6 lat w Polsce w roku 2012. Przegl Epidemiol 2014; 68: 139-142.

20. Turska-Szybka A, Soika I, Kalita M, et al. Dentition in children attending secondary school based on 2015 Monitoring of Oral Health and its Determinants in Mazovia Province. Part I. Dental caries. Nowa Stomatol 2016; 3: 181-192.

21. Gov.pl Serwis Rzeczypospolitej Polskiej. Monitorowanie stanu zdrowia jamy ustnej populacji polskiej na lata 2016-2020: Stan zdrowia jamy ustnej oraz potrzeby profilaktyczno-lecznicze dzieci w wieku 12 lat w 2012 r. https://www.gov.pl/web/zdrowie/monitorowanie-stanu-zdrowia-jamy-ustnej-populacji-polskiej-w-latach-2016-2020. Published 18.10.2012. Accessed 20.11.2019. 